\title{
SIMULASI KEMACETAN LALU LINTAS PADA LOKASI BUNDARAN BALTOS BANDUNG
}

\author{
Tresna Dewi, Farid Badruzzaman, Yusuf Fajar, Didi Suhaedi, Erwin Harahap \\ Email : tresnadewif@unisba.onmicrosoft.com, faridhb@unisba.ac.id, myusuffajar@unisba.ac.id, \\ dsuhaedi@unisba.ac.id,erwin2h@unisba.ac.id \\ Program Studi Matematika, Universitas Islam Bandung
}

\begin{abstract}
Abstrak
Pada masa kini perkembangan teknologi telah memacu meningkatnya kepemilikan kendaraan, terutama di beberapa kota seperti Jakarta, Bandung, Yogyakarta, dan kota besar lainnya. Situasi ini menimbulkan masalah yaitu kemacetan lalu lintas dimana salah satu penyebabnya adalah kepemilikan kendaraan yang semakin bertambah setiap tahun. Kondisi ini tidak didukung dengan keadaan infrastruktur dan sumber daya yang terbatas, disamping fasilitas lalu lintas yang pengoperasiannya masih belum optimal. Penyebab lain dari kemacetan lalu lintas ini adalah banyaknya angkutan umum yang sering berhenti sembarangan, keluar masuk area parkir, dan persilangan kendaraan di persimpangan. Oleh karena itu pada artikel ini dilakukan penelitian untuk mengetahui penyebab dalam masalah kemacetan dan diharapkan ditemukan solusi pemecahan masalah. Dalam penelitian ini, dirancang sistem simulasi arus lalu lintas dengan menggunakan aplikasi SimEvents yang dijalankan pada software MATLAB Simulink. Berdasarkan simulasi, dapat diprediksi penyebab kemacetan lalu lintas khususnya di lokasi Bundaran Balubur Town Square (BALTOS) Kota Bandung Jawa Barat.
\end{abstract}

Kata kunci : kemacetan, lalu lintas, simevents, matlab

\section{Pendahuluan}

Pada masa kini, perkembangan teknologi sudah semakin maju salah satunya dalam bidang transportasi baik di perkotaan maupun luar kota. Namun dengan kemajuan transportasi telah memicu meningkatnya jumlah kendaraan yang ada dan menimbulkan berbagai macam masalah. Salah satu masalah yang marak terjadi saat ini adalah kemacetan lalu lintas di Kota Bandung [1,2] khususnya di lokasi bundaran Balubur Town Square (Baltos) [3,4]. Kemacetan lalu lintas merupakan permasalahan yang sering terjadi akibat kepemilikan kendaraan yang semakin meningkat, terbatasnya sumber daya untuk pembangunan jalan raya, dan fasilitas lalu lintas yang pengoperasiannya masih belum optimal $[5,6]$. Saat ini kendaraan roda dua di Kota Bandung sebanyak tercatat sebanyak 1.251.080, unit dan roda empat berjumlah 536.973 unit. Jumlah ini meningkat sebesar $11 \%$ pertahunnya dengan didominasi kendaraan pribadi sebanyak 98\% [7].

Kemacetan dapat didefinisikan sebagai suatu proses yang tidak dapat bekerja dengan baik, tersendat, serat, terhenti, atau tidak lancar [8]. Kemacetan lalu lintas merupakan suatu masalah yang terjadi sebagai akibat dari pertumbuhan dan kepadatan penduduk, sedemikian sehingga arus kendaraan bergerak sangat lambat. Kemacetan lalu lintas terjadi setiap saat dan membuat lalu lintas Kota Bandung menjadi sangat tidak nyaman bagi para pengendara dan masyarakat disekitarnya $[9,10]$. Faktor lain penyebab kemacetan adalah banyaknya angkutan umum ataupun ojek daring yang sering berhenti sembarangan, keluar masuk area parkir kendaraan, dan arus kendaraan yang bersilangan di persimpangan tanpa lampu lalu lintas. Permasalahan ini sedikit terurai dengan adanya seseorang yang sukarela mengatur jalanan dengan tujuan agar lalu lintas bisa teratur, tetapi pada kenyataannya tidak berpengaruh cukup besar terhadap masalah kemacetan di lokasi tersebut. Penyebab kemacetan lainnya adalah para ojek daring yang menjadikan bahu jalan sekitar BALTOS sebagai tempat untuk standby atau menunggu orderan sehingga terjadi penyempitan jalan.

Pada artikel ini disusun simulasi kemacetan lalu lintas di sekitar Baltos dengan harapan dapat dianalisis dan ketahui penyebab dari kemacetan yang selanjutnya dapat diformulasikan solusi pemecahan masalah. Simulasi disusun dengan menggunakan aplikasi SimEvents [11,12] pada software MATLAB-Simulink [13,14]. Simulink merupakan fitur unggulan yang tersedia pada MATLAB, fitur ini adalah fitur khusus yang membedakan MATLAB dengan aplikasi berbasis matriks lainnya seperti FreeMat, Scilab, Octave, dan aplikasi lainnya. Simulink merupakan merupakan sebuah fasilitas yang terdapat pada MATLAB yang digunakan sebagai tools simulasi berbagai model, dimulai 
dari signal processing sampai dengan image processing, simulasi diskrit, dan sebagainya. Simulink dapat digunakan untuk membuat blok diagram berdasarkan sistem yang akan disusun. Simulasi atas suatu sistem berfungsi untuk mengurangi resiko kegagalan. Selain itu, melalui simulasi dapat dianalisis lebih awal terhadap suatu aturan atau kebijakan aturan lalu lintas yang akan diimplementasikan.

\section{Metode Penelitian}

Pada penelitian ini, data lalu lintas diperoleh melalui observasi langsung di jalan raya. Observasi dilakukan dengan cara mengamati keadaan lalu lintas sekaligus merekam keadaan lalu lintas ke dalam file video. Hal ini dilakukan untuk kemudahan dalam melakukan analisis data lebih lanjut agar hasil yang diperoleh lebih spesifik, realistis, dan akurat. Lokasi observasi yaitu di wilayah Baltos, Jalan Tamansari Bandung pada rentang waktu pukul $15.00 \mathrm{~s} / \mathrm{d} 18.00$ WIB. Pengambilan data dilakukan selama beberapa hari secara acak pada bulan Oktober hingga November 2019.

Simulasi arus lalu lintas dirancang untuk bisa mengetahui tingkat kemacetan lalu lintas dan diharapkan bisa menemukan solusi dari masalah tersebut. Rancangan simulasi ini membutuhkan beberapa variabel data, diantaranya rata-rata jumlah kedatangan kendaraan yang masuk dalam satuan waktu, dan rata-rata lama waktu kendaraan yang terhambat. Tahap selanjutnya, setelah data diperoleh dilakukan pemrosesan data. Data yang diperoleh yaitu rata-rata jumlah kendaraan yang masuk rata-rata 27 kendaraan/menit, dan rata-rata lama waktu kendaraan yang terhambat yaitu 0.03 menit. Rata-rata lama waktu kendaraan yang terhambat merupakan hasil akumulasi dari tiga hambatan di lokasi Baltos, yaitu persilangan kendaraan pada persimpangan bundaran, keluar masuk kendaraan area parkir, dan para ojek daring yang stand by di bahu jalan sekitar bundaran.

Data penelitian yang telah didapat dari hasil observasi langsung, disusun dalam MATLAB-Simulink menggunakan toolbox SimEvents. Berikut gambar rancangan simulasi arus lalu lintas:

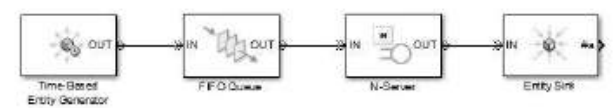

Gambar 1. Rancangan simulasi arus lalu lintas

Berdasarkan pada gambar 1 , simulasi arus lalu lintas dibangun oleh lima buah blok utama yaitu generator, link, queue, server, dan simEvents sinks. Generator berfungsi untuk menampung jumlah kendaraan yang masuk dalam satuan waktu tertentu. Link berfungsi sebagai penghubung antara blok satu ke blok lain. Queue berfungsi sebagai penampung antrian kendaraan. Server merupakan bagian pengelola proses kendaraan. SimEvents sinks berfungsi sebagai titik akhir kendaraan.

\section{Hasil dan Pembahas an}

Model simulasi arus lalu lintas disusun berdasarkan pada Gambar 1 untuk lokasi bundaran Baltos. Jalur yang dipilih adalah arus kendaraan yang berasal dari jalan Tamansari menuju persimpangan lampu merah Baltos. Peta jalur lalu lintas yang akan diimplementasikan pada simulasi ditunjukkan pada Gambar 2.

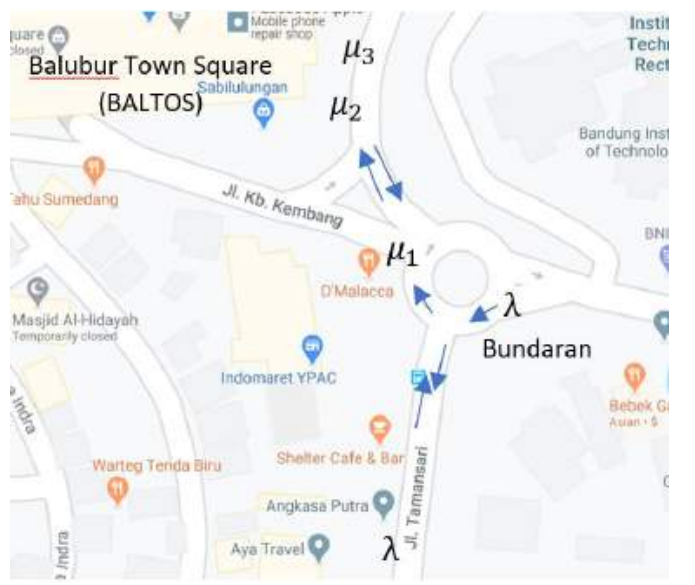

Gambar 2. Peta wilayah bundaran Baltos

Model simulasi juga disusun berdasarkan peta lalu lintas sekitar Baltos pada Gambar 2. Arus lalu lintas disusun dengan menggunakan lima buah blok utama sebagaimana ditunjukkan pada Gambar 1 yaitu generator sebagai penampung jumlah kendaraan yang masuk, link sebagai ruas jalan, quеие sebagai antrian, server sebagai hambatan kendaraan, sink sebagai titik akhir kendaraan. Lima buah blok utama tersebut kemudian dikembangkan menjadi sebuah sistem ditunjukkan pada Gambar 3. 


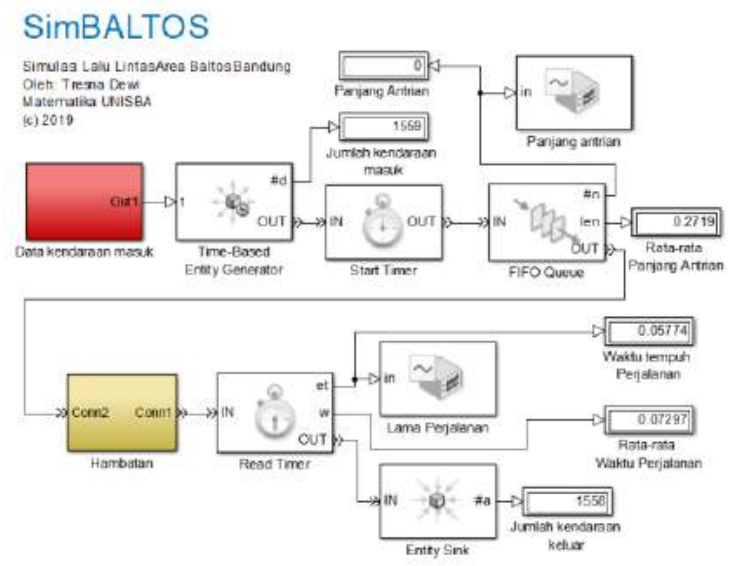

Gambar 3. Sistem Simulasi Arus Lalu Lintas untuk Bundaran Baltos

Berdasarkan pada model simulasi Gambar 3 terdapat blok Data Kendaraan Masuk dan blok Hambatan. Model lengkap untuk Data Kendaraan Masuk ditunjukkan pada Gambar 4, dan model lengkap untuk Hambatan ditunjukkan pada Gambar 5.

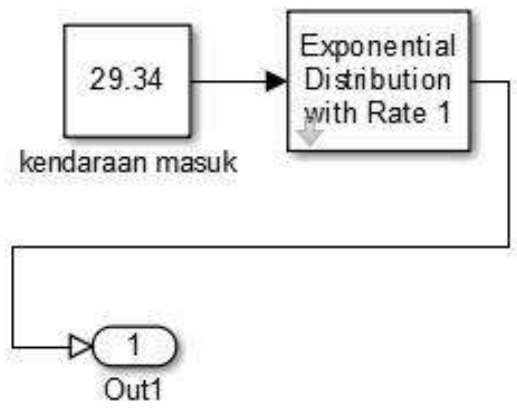

Gambar 4. Blok kendaraan masuk

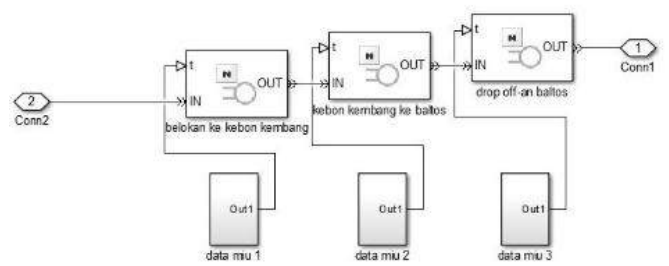

Gambar 5. Blok hambatan

Berdasarkan pengamatan diketahui bahwa kendaraan yang masuk pada arus jalan sekitar bundaran Baltos adalah rata-rata 27 kendaraan/menit. Jumlah kendaraan yang masuk memiliki komposisi 20 mobil dan 28 motor. Dalam penelitian ini untuk simplikasi, diasumsikan 4 unit motor setara dengan 1 unit mobil sehingga $28 / 4=7$ mobil. Dengan demikian jadi total keseluruhan 27 mobil, sehingga didapat:

$$
\begin{aligned}
& \boldsymbol{\lambda} \text { total }=\frac{\text { kendaraan }}{\text { waktu }}=\frac{27}{1 \text { menit }} \\
& =27 \text { kendaraan } / \text { menit }
\end{aligned}
$$

Pada gambar 5 terdapat tiga hambatan yang dinyatakan dalam variabel $\mu$ (mu). Hambatan pertama yaitu keluar masuk persilangan kendaraan di persimpangan jalan kb kembang - bundaran Baltos $\left(\mu_{1}\right)$, hambatan kedua yaitu keluar masuk Mall Baltos $\left(\mu_{2}\right)$, dan hambatan ketiga adalah ojek daring yang stand by di bahu jalan sekitar bundaran Baltos $\left(\mu_{3}\right)$. Gabungan seluruh hambatan atau mu total $(\mu)$ merupakan gabungan ketiga hambatan dimana

$$
\mu=\mu_{1}+\mu_{2}+\mu_{3}
$$

Rumus-rumus diatas diimplementasikan kedalam model simulasi bundaran Baltos (SimBALTOS). Berdasarkan pengamatan pada ketiga hambatan diatas, diperoleh data bahwa $\mu_{1}=0.024$ menit, $\mu_{2}=0.024$ menit, dan $\mu_{3}=$ 0.016 menit. Tahap selanjutnya adalah menjalankan aplikasi simulasi yang sudah dibangun. Hasil simulasi dengan variasi waktu running ditunjukkan pada Gambar 6 sampai dengan 9.
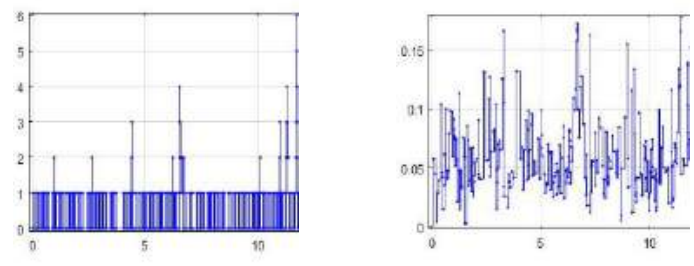

. Gambar 6. Panjang antrian dan waktu perjalanan pada simulasi 15 menit pertama
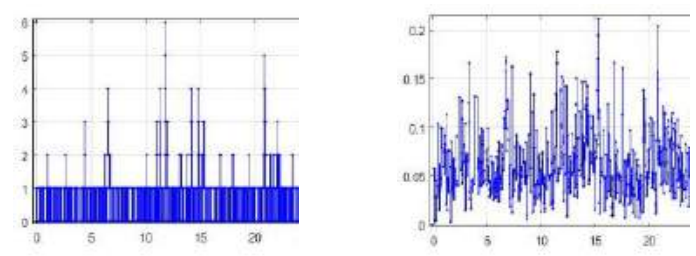

Gambar 7. Panjang antrian dan waktu perjalanan pada simulasi hingga 30 menit
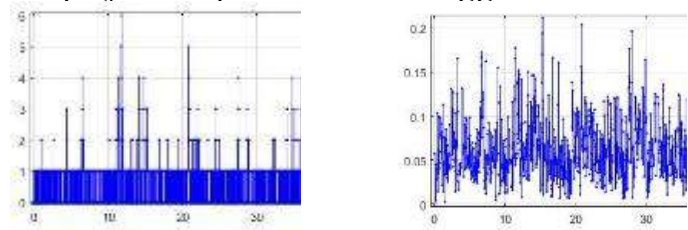

Gambar 8. Panjang antrian dan waktu perjalanan pada simulasi hingga 45 menit 

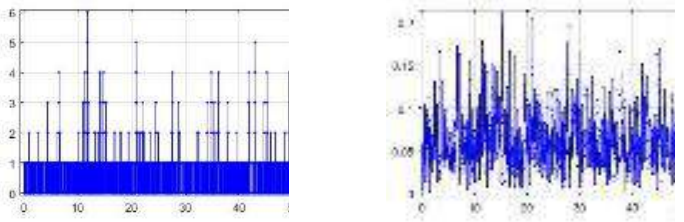

Gambar 9. Panjang antrian dan waktu perjalanan pada simulasi hingga 60 menit

Rata-rata hasil dari simulasi lalu lintas menggunakan SimBALTOS ditunjukkan pada Tabel 1 sebagai berikut:

\begin{tabular}{|c|c|c|c|}
\hline $\begin{array}{c}\text { Simul } \\
\text { asi } \\
\text { ke }\end{array}$ & $\begin{array}{c}\mathbf{t} \\
\text { (men } \\
\text { it) }\end{array}$ & $\begin{array}{c}\text { Rata- } \\
\text { rata } \\
\text { Panjang } \\
\text { antrian }\end{array}$ & $\begin{array}{c}\text { Rata-rata } \\
\text { Waktu } \\
\text { Perjalanan } \\
\text { (menit) }\end{array}$ \\
\hline 1 & 15 & 1 & 0.07 \\
\hline 2 & 30 & 1 & 0.09 \\
\hline 3 & 45 & 1 & 0.08 \\
\hline 4 & 60 & 1 & 0.07 \\
\hline
\end{tabular}

Sebagaimana ditunjukkan pada Tabel 1, hasil eksekusi dari aplikasi simulasi SimBALTOS menghasilkan arus lalu lintas padat lancar. Simulasi diuji-coba dengan kedatangan kendaraan mengikuti proses Poisson dan hambatan berdistribusi eksponensial. Karena model antrian yang digunakan adalah berjenis $\mathrm{M} / \mathrm{M} / 1$, dengan demikian durasi waktu simulasi tidak terlalu banyak berpengaruh terhadap panjang antrian dan waktu tempuh perjalanan.

\section{Kesimpulan}

Berdasarkan hasil simulasi dapat disimpulkan bahwa kemacetan yang ada di wilayah Baltos kota Bandung masih berada pada level padat lancar. Dengan implementasi data hasil observasi, menunjukkan panjang antrian dan waktu tempuh yang relatif pendek. Penelitian ini masih merupakan tahap awal, sehingga masih perlu ada perbaikan untuk hasil yang lebih realistis. Untuk penelitian dimasa yang akan datang disarankan untuk melakukan observasi lalu lintas yang lebih intensif pada waktu pagi dan siang, serta menambahkan waktu tempuh selain pada hambatan lalu lintas

\section{Daftar Pus taka}

[1] Raharja, Kerta, Bandung yang Semakin Macet, https://republika.co.id., Oktober 2019.

[2] Harahap, E., Badruzzaman, FH., Permanasari, Y., Fajar, MY., Kudus, A., LINTAS-BD 1.1: Model dan Simulasi Lalu Lintas Kota Bandung, ETHOS: Jurnal Penelitian dan Pengabdian 7 (2), 2019. h. 210-223
[3] Balubur Town Square, Bandung, http://www.kotakami.com., diakses Desember 2019.

[4] Chaeruddin, S., Fajar, Y., Harahap, E., Analisis Panjang Antrian Dampak Rekayasa Lalu Lintas Cipaganti Menggunakan SimEvents MATLAB, Jurnal JTIK (Jurnal Teknologi Informasi dan Komunikasi) 4 (1), 2020. h.8-11

[5] Hafizh, Naufal., Bandung Macet, Ridwan Kamil Minta Pusat Segera Memaksimalkan Anggaran, https://ayobandung.com., Oktober 2019.

[6] Harahap, E., Permanasari, Y., Badruzzaman, FH., Marlina, E., Suhaedi, D., Analisis Antrian Lalu Lintas Pada Persimpangan Buah Batu - Soekarno Hatta Bandung, Jurnal Matematika 17 (2), 2018.

[7] Andriyawan, Dea, Pertumbuhan Kendaraan di Bandung 11\% Per Tahun, https://bandung.bisnis.com., 2018.

[8] KBBI, Kamus Besar Bahasa Indonesia, https://kbbi.web.id., diakses Januari 2020.

[9] Mahardika, Dimas., Memanusiakan Warga Kota: Argumen Untuk Tidak Menambah Jalan Raya (Lagi), https://medium.com., 2019.

[10] Harahap, E., et.al., LINTAS-BD 1.2: Modeling and simulation traffic of Bandung City using SimEvents MATLAB, Journal of Physics: Conference Series (ISAMME 2019) 1315 (1), 2019.

[11] SimEvents, Model and simulate message communication and discrete-event systems, https://www.mathworks.com., accessed February 2020.

[12] Harahap, E., Nurrahman, A., Darmawan, D., A Modeling Approach For Event-Based Networking Design Using MATLABSimEvents, of International Multidisciplinary Conference (IMC) Proceedings, Jakarta, Indonesia, 2016.

[13] Simulink, Simulation and Model- Based Design, https://www.mathworks.com., accessed February 2020.

[14] Harahap, E., et.al., A Model-Based Simulator for Content Delivery Network using SimEvents MATLAB-Simulink, INSIST Journal 1 (1), 2016. h.30-33

[15] Harahap, E., Harahap, A., Suryadi, A., Darmawan, D., Ceha R., LINTAS: Sistem simulasi lalu lintas menggunakan SimEvents MATLAB, Jurnal Ilmiah Informatika dan Komputer 10 (1), 2018. h. $8-16$ 